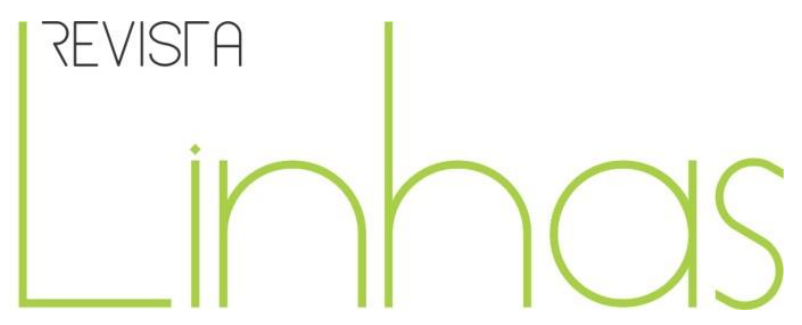

\title{
Do Estado de Bem-Estar Social ao neodesenvolvimentismo: considerações sobre o papel do Estado sob o capital
}

\section{Resumo}

O objetivo deste texto, resultado de pesquisa bibliográfica e documental, é apontar considerações a respeito das mudanças pelas quais passa o liberalismo, não obstante os diferentes níveis de proposição históricos e geopolíticos que demarcam sua trajetória desde o século XVIII, como por exemplo sua constante necessidade de afirmar e reafirmar as necessidades e interesses da sociedade capitalista, quer seja por meio da manutenção de uma agenda de reformas estatais estruturais, quer seja pela remodelagem de ideologias, como por exemplo a materializada no neodesenvolvimentismo. No que tange às condições necessárias para reprodução e manutenção das relações capitalistas de produção, discutimos o Estado burguês, tanto na forma do chamado Estado de Bem-Estar Social, quanto na forma de Estado pautada no ideário neoliberal. As premissas acima nos permitem refletir sobre a validade em discutirmos a continuidade do processo de reforma que atingiu o Estado e as práticas e instituições a ele relacionadas a partir da última década do século XX no Brasil, incluindo suas formas de organização e atuação, pois de acordo com o principal idealizador da reforma estatal, Luiz Carlos Bresser Pereira, uma reforma dessa envergadura necessita de trinta a quarenta anos para que sua efetividade seja completa.

Palavras-chave: Liberalismo. Reforma administrativa - Brasil. Projetos de desenvolvimento econômico - História - Brasil.
Isaura Monica Souza Zanardini

Universidade Estadual do Oeste do Paraná - UNIOESTE - Cascavel/PR Brasil

monicazan@uol.com.br

\section{João Batista Zanardini}

Universidade Estadual do Oeste do Paraná - UNIOESTE - Cascavel/PR Brasil

zanardini@uol.com.br

\section{Roberto Antonio Deitos}

Universidade Estadual do Oeste do Paraná - UNIOESTE - Cascavel/PR Brasil rdeitos@uol.com.br

\section{Para citar este artigo:}

ZANARDINI, Isaura Monica Souza; ZANARDINI, João Batista; DEITOS, Roberto Antonio. Do Estado de BemEstar Social ao neodesenvolvimentismo: considerações sobre o papel do Estado sob o capital. Revista Linhas. Florianópolis, v. 21, n. 46, p. 72-90, maio/ago. 2020. 


\title{
From the Welfare State to the neo-developmentism: considerations about the state's role upon the capital
}

\begin{abstract}
This text's objective, product of documental and biographical researches, is to point out considerations related the changes that liberalism is going through, despite the different levels of historical and geopolitical proposition that have marked its trajectory since the 18th century, such as its constant need to affirm and reaffirm the needs and interests of capitalist society, whether by maintaining an agenda of structural state reforms, or by reshaping ideologies such as that materialized in neo-developmentism. Regarding the necessary conditions for the reproduction and maintenance of capitalist relations of production, we discussed the bourgeois state, both in the form of the so-called Social Welfare State, and in the form of a State based on the neoliberal ideology. The above premises allow us to reflect on the validity in discussing the continuity of the reform process that reached the State and the practices and institutions related to it from the last decade of the 2oth century in Brazil, including its forms of organization, performance, because of According to the main creator of state reform, Luiz Carlos Bresser Pereira, a reform of this magnitude needs thirty to forty years to be effectively complete.
\end{abstract}

Keywords: Liberalism. Administrative reform - Brazil. Economic development - History - Brazil. 
O objetivo deste texto é apontar considerações a respeito das mudanças pelas quais passa o liberalismo, não obstante os diferentes níveis de proposição históricos e geopolíticos que demarcam sua trajetória desde o século XVIII, como por exemplo sua constante necessidade de afirmar e reafirmar as necessidades e interesses da sociedade capitalista, quer seja por meio da manutenção de uma agenda de reformas estatais estruturais, ou pela remodelagem de ideologias como por exemplo a materializada no neodesenvolvimentismo.

Importa assinalar, apoiados em Marx (1975, p. 144), que “O Estado e a organização da sociedade não são, do ponto de vista político, duas coisas distintas. O Estado é a organização da sociedade". No que tange às condições necessárias para reprodução e manutenção das relações capitalistas de produção, discutimos o Estado burguês, tanto na forma do chamado Estado de Bem-Estar Social, quanto na forma de Estado pautado no ideário neoliberal. Tais expressões são históricas e constituem-se em variantes ideológicas do Estado burguês. Desse modo, a ontologia que os embasa tem em vista a reprodução e manutenção das relações capitalistas de produção para as quais o Estado é indispensável, como afirma Mészáros (2003, p. 29): “[...] o sistema do capital não sobreviveria uma única semana sem o forte apoio que recebe do Estado".

Desse modo, discutimos aqui o papel do Estado na sociedade burguesa e as reformulações em seu papel propostas no contexto do Estado de Bem-Estar Social, neoliberalismo e neodesenvolvimentismo.

\section{Considerações sobre o Estado capitalista no Welfare State e no Neoliberalismo}

Levando-se em conta a necessidade e a essencialidade do Estado, particularmente do burguês, para o sistema do capital, reformá-lo, sempre que as condições objetivas o exijam, significa rever entraves e fatores de ineficiência para a reprodução desse modelo social. Para Mészáros, 
[...] o Estado se afirma como pré-requisito indispensável para o funcionamento permanente do sistema do capital, em seu microcosmo e nas interações das unidades particulares de produção entre si, afetando intensamente tudo, desde os intercâmbios locais mais imediatos até os de nível mais mediato e abrangente. (MÉSZÁROS, 2002, p. 109)

Considera-se necessário, no contexto da crise estrutural do capital, lançar mão de mecanismos de controle social, como os presentes no quadro da reforma do aparelho estatal. Mészáros (2002, p. 120) assinala que a reforma do Estado se pauta na valorização da mitologia do mercado, e explica que:

A condição material necessária para afirmar com sucesso o imperativo estrutural expansionista do capital é a constante extração do trabalho excedente de uma forma ou de outra, de acordo com as mudanças das circunstâncias históricas. No entanto, devido à determinação centrífuga dos constituintes reprodutivos econômicos do capital, sem levar em conta seu maior ou menor tamanho (chegando até as gigantescas corporações transnacionais quase monopolistas), eles são incapazes de realizar por si sós o imperativo estrutural do capital, pelo fato de thes faltar a determinação coesiva essencial para a constituição e o funcionamento sustentável de um sistema sociometabólico. É este inexistente princípio coesivo ordenador dos constituintes econômicos básicos que é conceituado, até mesmo pelos maiores pensadores que enxergam o mundo do ponto de vista do capital, como a misteriosa "mão invisível" de Adam Smith e a "astúcia da Razão" de Hegel. É assim que surge a mitologia do mercado, não apenas como regulador suficiente, mas até como regulador global ideal do processo sociometabólico. (MÉSZÁROS, 2002, p. 120)

As premissas acima nos permitem refletir sobre a validade em discutirmos 0 processo de reforma que atingiu o Estado e as práticas e instituições a ele relacionadas a partir da última década do século XX no Brasil, incluindo suas formas de organização, atuação e avaliação'. O movimento de reformulação do seu papel - diversamente realizado - indicou a incapacidade de o Estado reger direta e completamente o desenvolvimento. Fato ilustrativo é o índice de pobreza e desemprego estrutural que persegue o fato de que, como disse Luiz Carlos Bresser Pereira, em artigo intitulado "Os

\footnotetext{
${ }^{1}$ Entre as razões que explicam a demanda pela reforma do Estado está a impossibilidade, demonstrada ad nauseam, de realização das promessas de desenvolvimento econômico, especialmente nos países periféricos.
} 
primeiros passos da Reforma gerencial do estado de 1995", uma reforma dessa envergadura necessita de trinta a quarenta anos para ser efetivamente completa:

Nestes quinze anos, a reforma gerencial de 1995 fez importantes avanços, mas naturalmente não transformou do dia para a noite a organização do Estado brasileiro; uma reforma desse tipo leva de 30 a 40 anos para poder ser julgada relativamente completa. Já não é mais apenas uma reforma de uma pessoa ou de um governo, mas uma reforma adotada e conduzida pela alta administração pública brasileira uma reforma que começou no governo Fernando Henrique está sendo continuada e atualizada pelo governo Lula e os atuais governadores, e certamente terá prosseguimento independentemente de quem sejam seus sucessores. Além de as práticas gerenciais continuarem a se expandir no governo federal, estão sendo criadas organizações sociais uma inovação institucional importante da reforma gerencial de 1995 à qual, na época na oposição, o PT se opôs. (BRESSER PEREIRA, 2010, p. 174)

Como forma de compreender a constante retórica que afirma a necessidade de reformulação estatal, podemos partir do então chamado Estado de Bem-Estar Social Welfare State, que também não se materializou da mesma forma no mundo, chegando inclusive a inexistir em alguns países, mas que em sua raiz carrega a retomada dos princípios liberais defendidos por Adam Smith no século XVIII a fim de consolidar um modelo social dito aberto, passível de ascensão e capaz de valorizar o indivíduo nas suas capacidades e, assim, suplantar o modelo social estático característico da sociedade feudal, que ao longo da história sofre inflexões mantendo em seu cerne os mesmos princípios ideologizantes.

A crise do Estado de Bem-Estar Social, ou a derrota do Keynesianismo ${ }^{2}$ é seguida pela afirmação do neoliberalismo que ganha forças a partir do pensamento de $\mathrm{Hayek}^{3} \mathrm{e}$ Milton Friedman', os quais são os responsáveis pela constituição de um caráter acadêmico à retomada dos preceitos liberais para os quais a força "mágica” que regularia a sociedade seria a "mão invisível do mercado", que atuaria regendo as relações que os

\footnotetext{
${ }^{2}$ Marco da crise estrutural que determinou o fim dos "trinta gloriosos" anos do capitalismo fordista ou do Estado de Bem-estar social. Os mecanismos de ajuste keynesianos não lograram o êxito do decênio anterior e seus pressupostos foram atacados pelos neoliberais favoráveis à regulação da economia pelo mercado.

3 Friedrich August von Hayek economista e filósofo austríaco, posteriormente naturalizado britânico. Um dos maiores representantes da Escola Austríaca de pensamento econômico.

${ }^{4}$ Um dos principais economistas do século XX e líder da Chicago School of Monetary Economics.
} 
indivíduos estabeleceriam entre si concorrendo para o bem geral, gerando eficiência, justiça e, sobretudo, riqueza. Dessa maneira, a disciplina anônima da concorrência substituiria supostamente a disciplina visível das hierarquias ${ }^{5}$.

De acordo com Moraes (1997), pode-se afirmar que as principais ideias liberais “renascem” no século XX, com o neoliberalismo, cuja pedra fundamental está na obra $O$ caminho da servidão, de Friedrich von Hayek, publicada em 1944. Nela, Hayek pretendeu esclarecer o seu caráter anti-absolutista, indo de encontro a um conjunto formado pelo Estado de Bem-Estar, planificação e intervenção estatal na economia, elementos identificados com a teoria Keynesiana6.

Sobre a obra O Caminho da servidão, Moraes afirma:

Livro de combate, provocativamente endereçado "aos socialistas de todos os partidos", O Caminho da Servidão não dirige seu fogo apenas contra os partidários da revolução e da economia globalmente planificada, mas a toda e qualquer medida política, econômica e social que indique a mais tímida simpatia ou concessão para com as veleidades reformistas, pretensões de "terceira via" etc. Lembremos, de passagem, que as eleições estavam próximas na Inglaterra, e o partido trabalhista, alvo visível de Hayek, preparava-se para ganhá-las (e ganhou, em 1945). Sublinhemos ainda este traço que viria a ser marcante no fundamentalismo hayekiano: a insistência na necessidade de guardar intactos, radicalmente, os princípios da "sociedade aberta", centrados numa implacável crítica do Estado- providência, tido como destruidor da liberdade dos cidadãos e da competição criadora, bases da prosperidade humana. (MORAES, 1997, p. 6)

\footnotetext{
${ }^{5}$ Moraes ao tratar dos ideais de Adam Smith referentes aos entraves sociais que impediam a "emergência de indivíduos criativos e empreendedores", afirma que "A argumentação de Smith é clara. É necessário que a disciplina anônima da concorrência substitua a disciplina visível das hierarquias arcaicas - estejam estas hierarquias encarnadas em obrigações tradicionais e personalizadas do medievo ou nos regulamentos fixados pelas corporações e pelo estado mercantilista. Elogia-se a virtuosa mão invisível do mercado contra a viciosa mão visível do poder político" (MORAES, 1997, p. 7).

${ }^{6}$ Conforme Moraes (1997, p. 16): “O liberalismo clássico havia assentado baterias contra o Estado Mercantilista e as corporações. Os novos cruzados da livre-iniciativa pretenderam desde logo construir um análogo daquele mundo, para justificar seu combate e apresentá-lo como a continuação de uma respeitável campanha anti-absolutista. Os inimigos agora recebem outros trajes, mas revelariam taras ancestrais e perversões reiteradas. Um desses inimigos é o conjunto institucional composto por Estado de Bem-Estar, planificação, intervenção estatal na economia, tudo isso identificado com a doutrina keynesiana. Outro inimigo é localizado nas modernas corporações - os sindicatos e centrais sindicais, aliás também paulatinamente integrados (e esse é o problema...) no conjunto institucional anteriormente mencionado, já que, além de sabotar as bases da acumulação privada, através de reivindicações salariais, os sindicatos teriam empurrado o Estado a um crescimento parasitário através da imposição de despesas sociais e investimentos sem perspectiva de retorno".
} 
Segundo Moraes,

Brilharia, nessa ocasião, a filosofia social exposta por John Maynardes Keynes no final de sua Teoria Geral, livro publicado em 1936, mas que, em várias de suas passagens, retomava problemas que Keynes vinha analisando desde os anos 20. Na doutrina Keynesiana, o Estado manejaria grandezas macroeconômias sobre as quais era possível acumular conhecimento e controle prático, regulando oscilações de emprego e investimento, de modo a moderar crises econômicas e sociais. O New Deal norte-americano e o Estado de Bem-Estar europeu iriam testar (e aprovar durante bom tempo) a convivência do capitalismo com um forte setor público, negociações sindicais, políticas de renda e seguridade social etc. (MORAES, 1997, p. 18)

Para Anderson (1995), Hayek considerava como oponentes do neoliberalismo as modernas corporações, tais como sindicatos ou centrais sindicais, acusados de sabotar as bases da acumulação privada, empurrando o Estado a um crescimento doentio, com o acarretamento de despesas sociais e investimentos, na lógica do mercado, sem retorno, manifestando assim a preferência pela via privado-mercantil. Com relação ao Estado de Bem-Estar, Anderson (1995, p. 10) assinala que "Hayek e seus companheiros argumentavam que o novo igualitarismo (muito relativo, bem entendido) deste período, promovido pelo Estado de Bem-Estar, destruía a liberdade dos cidadãos e a vitalidade da concorrência, da qual dependia a prosperidade de todos." A teoria de Estado neoliberal se assenta num aparente paradoxo, que consiste basicamente em apregoar um modelo de Estado que seja ao mesmo tempo forte e fraco. Como demarca Anderson,

O remédio, então, era claro: manter um Estado forte, sim, em sua capacidade de romper com o poder dos sindicatos e no controle do dinheiro, mas parco em todos os gastos sociais e nas intervenções econômicas. A estabilidade monetária deveria ser a meta suprema de qualquer governo. Para isso seria necessária uma disciplina orçamentária, com a contenção dos gastos com bem-estar, e a restauração da taxa "natural" de desemprego, ou seja, a criação de um exército de reserva de trabalho para quebrar os sindicatos. (ANDERSON, 1995, p. 11)

Assim, os neoliberais se afirmaram como portadores da verdadeira doutrina capitalista e empreenderam reformas para a superação da crise estrutural na qual mergulhara o capitalismo. Essa crise, tratada como crise do Estado de Bem-estar Social, 
tem nas suas raízes motivos políticos e econômicos em que o padrão de Estado neoliberal, delineado a partir da década de $1970^{7}$, é propalado como instrumento capaz de reconstituir e reafirmar os interesses do modo de produção capitalista. Tais reformas configuraram uma "nova era", a Era do livre mercado, na qual todas as coisas ou são tratadas como mercadorias, se assim puderem ser convertidas, ou são tratadas pelo crivo da lógica do mercado independentemente de sua natureza social não se ajustar diretamente ao mundo das mercadorias.

Trataremos, então, das principais caraterísticas do modelo econômico e político neoliberal com a finalidade de, na sequência, tecermos considerações a respeito do chamado novo desenvolvimentismo ou neodesenvolvimentistmo, que seria a nosso ver, a atual configuração ideológica do liberalismo em sua necessidade de mais uma vez, reafirmar a continuidade das relações capitalistas de produção, se necessário revestindo de novos vernizes velhas ideologias.

\section{Do Estado de Bem-Estar Social ao Neodesenvolvimentismo}

Para compreender as mudanças pelas quais passa o liberalismo a fim de continuar, como diz Mirian Warde (1984), acompanhando e legitimando o capitalismo em suas diferentes fases de atuação, precisamos considerar o já mencionado Estado de Bem-Estar Social que se constituiu, sobretudo na Europa Ocidental e parte da América do Norte, a partir dos anos 30 do século XX, durante uma das crises cíclicas do capitalismo, período que ficou conhecido como a Crise de 29 ou a Grande Depressão, e que propõe a intervenção do Estado na regulação da economia e a ampliação do atendimento aos direitos sociais.

As teses do economista John Maynardes Keynes partiam do pressuposto de que para recuperar-se da crise e alavancar novamente o desenvolvimento econômico, era necessário deixar de lado a incompetência da lógica do mercado que teria sido a sua responsável e sugerem que para superar esse período e sustentar o padrão de sociedade capitalista, era necessário assegurar a atuação do Estado na regulação da economia e

\footnotetext{
7 No Brasil, o Estado neoliberal se consolidou a partir do início da década de 1990.
} 
colocar em prática algumas ações voltadas para o atendimento de necessidades sociais e assim, conter o avanço do Estado soviético sobre os países centrais e periféricos.

Entretanto, cabe considerar que o Estado de Bem-Estar Social

[...] representou uma criação do capitalismo, foi possível em determinado momento do capitalismo, surgindo sobretudo nos países, onde o crescimento no pós - $2^{\text {a }}$ Guerra Mundial (1945) foi muito acentuado. Não existiu Estado de Bem-Estar Social fora desses países e ele começou a morrer com a crise a partir da década de 70. É um cadáver que passeia pelos livros, mas expirou historicamente e só foi possível em países altamente capitalizados. (VIEIRA, 2001, p. 20)

Corroborando o papel que o Estado e as políticas públicas, como resultado das relações de produção, realizam na sociedade capitalista, as políticas implementadas pelo Estado para atender necessidades sociais, "amenizavam", de certo modo, os problemas sociais e atenderiam necessidades da classe trabalhadora, mas ao mesmo tempo asseguram a necessidade de consumo inerente à sociedade capitalista, uma vez que ao receber subsídios para o atendimento de algumas necessidades sociais, o trabalhador poderia dispor de recursos para o consumo das mercadorias produzidas em grande escala.

O esgotamento do padrão de Estado de Bem-Estar Social, manifesta-se, segundo Bianchetti,

[...] com maior intensidade no momento em que, nas sociedades desenvolvidas do capitalismo central, se produz o fenômeno conhecido como estagflação (estancamento econômico com inflação), que rompe com a lógica keynesiana de que a ação reguladora do Estado tinha por objetivo impedir as crises cíclicas do capitalismo. A partir disso, e como resultado da falta de propostas, cobram novamente vigência as teorias que sustentam a idéia contrária sobre a participação do Estado na economia. (Bianchetti, 1996, p. 24)

Portanto, com a crise do chamado Estado de Bem-Estar Social - provocada por razões políticas e econômicas, o neoliberalismo que no Brasil se consolida na década de 1990, é tomado como a única possiblidade de retomar os interesses do modo de produção capitalista. 
O neoliberalismo constitui-se em meio ao chamado processo de internacionalização da economia e propõe a liberdade de mercado em contraposição à regulação do Estado presente no Welfare State.

A respeito do contexto que produz a retomada do liberalismo, o economista José Luis Fiori escreve:

[...] Não é fácil encontrar na história outro momento em que a riqueza e o poder mundiais tenham se somado e concentrado de maneira tão gigantesca como neste final de século. Nem há, na modernidade capitalista, outra época em que a distância entre as nações crescesse tão rapidamente como nesses últimos vinte anos. A economia americana cresce há nove anos sem parar; os europeus crescem muito menos e a menos tempo, enquanto o resto do mundo - com exceção da China parece estatelado, ora entrando, ora saindo de mais uma crise. (FIORI, 2001, p. 51)

A respeito desse momento, Mészáros (2003) considera como a fase mais perigosa do imperialismo, na qual para afirmar-se como "Estado do sistema do capital por excelência", e impor ao mundo o seu arbítrio e a sua racionalidade, os Estados Unidos lançam mão de diferentes artifícios ideológicos, como por exemplo o domínio dos órgãos de intercâmbio econômico, e até mesmo da violência militar, incluindo-se aqui a violência processada a partir das armas nucleares.

De acordo com Fiori (2001), o neoliberalismo do século XX apresenta algumas semelhanças com o liberalismo do século XVIII. Dentre elas, este autor chama atenção para suas teses centrais: o menos de Estado e de política possível (despolitização dos mercados, liberdade de circulação dos indivíduos e dos capitais privados), defesa do individualismo e igualdade, referindo-se à igualdade de oportunidades ou condições iniciais iguais para todos.

O que se constata via defesa do "menos de Estado e de política possível" não é a supressão do papel do Estado na regulação das relações sociais capitalistas, mas uma redefinição da atuação do Estado a fim de superar uma suposta crise de eficiência na administração da coisa pública e possibilitar a realização dos princípios do liberalismo. Conforme Milton Friedman: 
A existência de um mercado livre não elimina, evidentemente, a necessidade de um governo. Ao contrário, um governo é essencial para a determinação das regras do jogo e um árbitro para interpretar e pôr em vigor as regras estabelecidas. $O$ que o mercado faz é reduzir a extensão em que o governo tem que participar diretamente do jogo. $O$ aspecto característico da ação política é o de exigir e reforçar uma conformidade substancial. A grande vantagem do mercado, de outro lado, é a de permitir uma grande diversidade, significando, em termos políticos, um sistema de representação proporcional. Cada homem pode votar pela cor da gravata que a deseja e a obtém, ele não precisa ver que cor a maioria deseja e então, se fizer parte da minoria, submeter-se. (FRIEDMAN, 1962, p. 23)

O que se esperava, portanto, dessa redefinição do papel do Estado é que ele pudesse [...] fazer alguma coisa que o mercado não pode fazer por si só, isto é, determinar, arbitrar e por em vigor as regras do jogo." (FRIEDMAN, 1962, p. 33). Esse Estado "árbitro do jogo" seria o único capaz de coexistir ao lado de uma sociedade que também segundo Friedman, exerceria a "cooperação voluntária entre os indivíduos", deixando de lado o caminho da servidão a que fizera referência Friedrich Hayek.

Na análise de Behring:

O neoliberalismo não minimizou a intervenção do Estado, conforme seus anúncios de primeira hora, pois esse permaneceu com forte presença econômica e social, e intensa capacidade extrativa, já que não diminuiu a carga tributária na maior parte dos países. pelo contrário. Tudo indica que a diminuição do "peso" do Estado vinculou-se mais às privatizações e a diminuição da tributação sobre os ricos, mas sem diminuir a carga tributária [...]. O Estado, então, redireciona a alocação do fundo público, sendo elemento constitutivo dessa lógica destrutiva. (BEHRING, 2018, p. 50)

Uma das principais reformas propostas pelo neoliberalismo diz respeito à reforma no papel do Estado, que passaria de promotor do crescimento e desenvolvimento para regulador e avaliador, incentivando a privatização de serviços e a participação social na promoção dos direitos sociais.

No Brasil, temos a partir de 1995, durante a gestão do Presidente Fernando Henrique Cardoso, a implementação da Reforma do Estado Brasileiro impulsionada pelo Ministro da Administração Federal e Reforma do Estado, Luiz Carlos Bresser Pereira. Questionando a administração burocrática para a administração dos serviços sociais e 
seguindo a premissa liberal de Adam Smith de que determinados serviços não poderiam ser integralmente oferecidos à população pelo Estado, Bresser Pereira propõe a divisão dos setores de propriedade dos serviços oferecidos pelo Estado, criando o chamado setor não exclusivo, legitimando a ação de organizações privadas e não estatais, em atividades que envolvem os diretos humanos fundamentais e incentivam a implementação da chamada administração pública gerencial, para substituir a administração burocrática.

Destaque-se, entretanto, que, de modo a não abandonar o necessário papel de árbitro do jogo como defendia Milton Friedman, fica reservado à propriedade exclusiva do Estado e à administração burocrática, os setores que definem as leis e as políticas públicas e cobram o seu cumprimento.

No contexto da segunda década dos anos 2000, mediante uma nova crise do capitalismo e crise do neoliberalismo na América Latina e, estando a presidência do Brasil sob a direção de um partido supostamente associado aos interesses da classe trabalhadora, o liberalismo vive uma nova reformulação, que a nosso ver associa os interesses da denominada Terceira Via,

Pois nesse ponto que se localiza o papel político das organizações do Terceiro Setor de contestação a um sistema global anônimo não personificada.Uma das facetas na qual estão apoiadas é sobre a suposta abolição da separação entre esquerda e direita, conceitos "obsoletos" com o fim do bi-polarismo, lutando-se pela "superação" dos problemas gerados pelo sistema capitalista, mas no sentido de sua melhoria, não de chegada a outro sistema. Não se deve falar em igualdade social (proveniente de uma semântica de "esquerda", que pregava a propriedade coletiva dos meios de produção), mas em justiça social (que pela nova semântica traduz que o progresso coletivo é alcançado quando as iniciativas individuais voltam suas atenções para as injustiças causadas pela sociedade), cujas soluções passaram a repousar na iniciativa individual (via institucionalização por organizações do Terceiro Setor, veículos de expressão da "sociedade civil"), empresarial (pela crescente imputação dos ditames da "responsabilidade social") e governamental (regulador e parceiro das forças de mercado, assim como entre o aspecto econômico e o não-econômico na vida da sociedade). (CALEGARE; SILVA JÚNIOR, 2009, p. 144-145) 
Essa nova reformulação liberal produzida já no contexto do neoliberalismo, impulsionada pelos trabalhos do ex-ministro Bresser Pereira, é marcada em grande medida por uma retomada da intervenção e planejamento estatal que foram valorizados anteriormente no escopo do Estado de Bem-Estar Social: trata-se do neodesenvolvimentismo ou novo desenvolvimentismo, cujo desafio, consiste segundo Sampaio Jr:

[...] em conciliar os aspectos "positivos" do neoliberalismo compromisso incondicional com a estabilidade da moeda, austeridade fiscal, busca de competitividade internacional, ausência de qualquer tipo de discriminação contra o capital internacional - com os aspectos "positivos" do velho desenvolvimentismo - comprometimento com o crescimento econômico, industrialização, papel regulador do Estado, sensibilidade social. (SAMPAIO JR, 2012, p. 679)

O neodesenvolvimentismo, uma reformulação do neoliberalismo, é marcado pela ação do Estado na alegação de diminuir a pobreza a partir do principio da equidade social enquanto igualdade de oportunidades, tendo em vista aumentar o crescimento nacional e favorecer a relação com os países de capitalismo central, sem contudo interferir na posição que o país ocupa na divisão internacional do trabalho.

Para os novo desenvolvimentistas:

[...] a construção de uma economia de mercado forte depende da existência de um Estado forte, não no sentido de produzir bens e serviços diretamente a partir de empresas estatais, mas atuando como uma instância reguladora das atividades econômicas. O Estado seria uma espécie de ente político promotor de condições propícias para o capital investir seus recursos financeiros e gerar emprego e renda para a população em geral. (BRANCO, 2009, p. 77)

Essa configuração do Estado, bem como uma determinada necessidade de melhorar as condições de vida de parte da população para possibilitar o desenvolvimento econômico, exige a ampliação da participação social na promoção de direitos sociais.

O caráter ideológico desse movimento é desnudado por Sampaio Jr, ao afirmar que nele, são desconsiderados: 
[...] diversos componentes do ajuste liberal (processo de liberalização, desregulamentação e privatização, estabilidade da moeda, Lei de Responsabilidade Fiscal,superávits primários, limite ao endividamento do setor público, ataque aos direitos trabalhistas), como também os efeitos da ordem global sobre as condições de funcionamento da economia brasileira (livre mobilidade dos capitais, perda de soberania monetária, impotência dos centros internos de decisão diante dos movimentos especulativos do capital internacional, restrição a expansão do mercado interno, bloqueios à política industrial, antagonismo entre políticas macroeconômicas e gasto público, concorrência entre políticas sociais universalistas e políticas sociais assistencialistas). (SAMPAIO JR, 2012, p. 682-683)

Ao tratar do neodesenvolvimentismo, consideramos que em certa medida, retoma a preocupação com o atendimento focal de direitos sociais, materializado numa política assistencialista, que também era uma das características do Estado de Bem-Estar Social. O que chama atenção é que agora, há um recrudescimento da força assistencialista.

Desse modo, segundo lamamoto,

[...] são devolvidos aos usuários os serviços sociais de direito: saúde, educação, política salarial, trabalho, habitação, lazer e outros, como benesse, assistência, filantropia, favor, ou seja, medidas parcelares e setoriais que o Estado oferece nas questões sociais para manter $o$ controle e a ordem social. Essa ação paternalista do Estado tende a inibir crises sociais e legitimam seu discurso demagógico de cooperação entre as classes sociais e o ajustamento da classe trabalhadora às regras do modelo neoliberal. (Iamamoto, 2002, p. 97-8)

Dessa maneira, a sociedade passa a ser concebida de forma dividida em setores, para os quais cabem diferentes funções sociais; aquelas ligadas diretamente ao interesse do mercado, as funções desligadas deste, e as que cabem ao setor que substituiria a ação do Estado na manutenção social, em que destacam-se diferentes entidades da sociedade civil.

Para Bravo e Correia:

A partir dessa suposta oposição entre Estado e sociedade civil, a expressão controle social é cunhada. Ressalta-se a importância de desvendar de que sociedade civil está falando para qualificar esse controle social, principalmente a partir das novas formulações de sociedade civil, no final dos anos 1980, postas pelo ideário neoliberal, que 
conduzem a um esvaziamento e à despolitização no trato da mesma. (BRAVO; CORREIA, 2012, p. 130)

Partimos do pressuposto de que no espaço da sociedade civil são ajustados os interesses privados ligados sempre a uma determinada classe social que não necessariamente se interligam oficialmente ao Estado. Apoiados em Gramsci (1999, p. 2021), que trata as entidades pertencentes a esse espaço como componentes de uma organização complexa da sociedade, entendemos a sociedade $\mathrm{civil}^{8}$ como "o conjunto de organismos comumente chamados de privados, onde a hegemonia e o consentimento espontâneo são organizados" podendo, inclusive, por meio de uma hipertrofia, organizar os grupos componentes da sociedade política na defesa de interesses de determinados grupos sociais em detrimento de outros, quadro que se acirra em sociedades economicamente periféricas na contemporaneidade.

Tal defesa particularista é feita sempre em nome do bem comum, ou do bom andamento da sociedade, discurso esse que é peremptoriamente repetido pelos arautos contemporâneos da continuidade das reformas no aparelho do Estado, a exemplo do FMI:

A janela de oportunidade está aberta. Para manter o ímpeto da economia, os países precisam controlar os riscos financeiros e fiscais, aumentando a resiliência do setor financeiro e reconstruindo o espaço para a aplicação de políticas; precisam também avançar nas reformas estruturais que fortalecerão a economia contra futuras tempestades. Devem promover um sistema de comércio multilateral aberto e baseado em regras e procurar garantir que as novas tecnologias beneficiem a todos - estimulando, e não dificultando, o crescimento inclusivo e a estabilidade financeira. (FMI, 2018, p. 6)

E dentre os argumentos de ineficiência do Estado, construiu-se também a necessidade de seu ajustamento a fim de que, abandonando a função de promotor direto do crescimento (característica do Estado desenvolvimentista e nacional), passasse a atuar

\footnotetext{
${ }^{8}$ De acordo com Fontes (2009): Na atualidade, há intensas lutas na sociedade civil (no sentido formulado por Gramsci), que também se traduzem em disputas em torno do próprio conceito. Entidades mantidas por setores empresariais (como associações empresariais, fundações e think tanks) retomaram o conceito liberal e se apresentaram como 'sociedade civil', como se fossem distintas e contrapostas ao Estado (e aos governos) dos quais participam. O termo Organização Não Governamental, cunhado na ONU em 1945, fluido e ambíguo, contribuiu para diluir o sentido social dessas entidades.
} 
como catalisador e facilitador do crescimento, mesmo que associado de forma dependente, cumprindo o ditame de passos no sentido de sua pseudo-modernização subordinada. No Brasil e em outros países periféricos, a essa perspectiva denominou-se como “Estado mínimo”, mínimo no fomento, ao mesmo tempo em que máximo na regulação e controle do social.

O advento da globalização financeira ${ }^{9}$ e a sua propagação revelaram a importância atribuída à expansão dos mercados, sobretudo naqueles pautados em capital financeiro e que desembocaram diretamente no diagnóstico de alteração da função do Estado.

Dentro da linha de redefinição do papel do Estado, a contrarreforma, sob orientação do Banco Mundial, propõe a descentralização como deslocamento de responsabilidade para a sociedade e esta passa a ser co-responsável pelos serviços e pela gestão pública por meio da "participação da comunidade". A estratégia é a busca de parcerias com a sociedade para que esta assuma os custos da crise, repassando-se assim a responsabilidade pela prestação de serviços sociais de competência do Estado para Organizações Não Governamentais (ONGs), instituições filantrópicas, comunitárias, entre outras. Desta forma, o Estado reduz o seu papel de prestador direto dos serviços, reorientando sua intervenção como regulador e provedor financeiro. (BRAVO; CORREIA, 2012, p. 131)

Entendemos que essa valorização da participação da comunidade, preconizada pelos organismos internacionais, diz respeito à lógica da gestão compartilhada já recomendada nos anos 1990 e que nos nossos dias ainda se mostra como aquela capaz de superar a ineficiência e promover a modernização da gestão. Essa prática de gestão significa além da divisão de responsabilidades financeiras, a responsabilização pelos resultados presente nos ajustes propostos desde a década de 1990.

\footnotetext{
9 Para Chesnais (1996, p. 17), "A expressão 'mundialização do capital' é a que corresponde mais exatamente à substância do termo inglês 'globalização', que traduz a capacidade estratégica de todo grande grupo oligopolista, voltado para a produção manufatureira ou para as principais atividades de serviços, de adotar, por conta própria, um enfoque e conduta 'globais'. O mesmo vale na esfera financeira para as chamadas operaç̃̃es de arbitragem. A integração internacional dos mercados financeiros resulta, sim, da liberalização e desregulamentação que levaram à abertura dos mercados nacionais e permitiram sua interligação em tempo real. Mas baseia-se, sobretudo, em operações de arbitragem feitas pelos mais importantes e mais internacionalizados gestionários de carteiras de ativos, cujo resultado decide a integração ou exclusão em relação às 'benesses das finanças de mercado'. Como veio lembrar a crise mexicana de 1994-1995, basta pouca coisa para que um lugar financeiramente 'atraente' deixe de sê-lo em questão de dias e, de certa forma, fuja da órbita da mundialização financeira”.
} 


\section{Considerações finais}

Nosso propósito neste artigo foi tecer considerações a respeito do papel do Estado levando em consideração algumas mudanças pelas quais passa o liberalismo, as quais podem ser constatadas desde o Estado de Bem-Estar Social até o neodesenvolvimentismo, tendo em vista assegurar seu papel político e ideológico na reprodução das relações capitalistas de produção e afirmar a indispensabilidade do papel do Estado para tais relações.

Desse modo, partimos do papel do Estado burguês neste modelo social e procuramos tratar da proposição para o seu papel mediante a relação com o atendimento dos chamados direitos sociais no Estado de Bem-Estar Social, no neoliberalismo e no neodesenvolvimentismo que tratamos aqui como uma reformulação ideológica do neoliberalismo.

Não obstante o padrão de Estado, a fim de assegurar seu caráter de classe, a implementação de políticas sociais sofre as implicações das finalidades econômicas, políticas e ideológicas do imperialismo e tem em vista a ampliação do controle sobre a classe trabalhadora.

No contexto do neoliberalismo e do neodesenvolvimentismo, evidencia-se o acirramento de reformas no âmbito do Estado e, embora tenham se passado décadas desde a elaboração do Plano Diretor da Reforma do Aparelho do Estado, constatamos que temos sempre "mais do mesmo", ou seja: permanecem as recomendações para superar a crise de eficiência do Estado, modernizar a gestão pública, enxugar os gastos sociais do Estado e envolver a sociedade civil no atendimento dos direitos sociais.

Esse envolvimento é justificado por um duplo interesse: financeiro e ideológico. Com a promoção de direitos sociais por alguns setores da sociedade civil, reorganizam-se as finanças do Estado e assegura-se que o setor privado imprima seus interesses, finalidades e demandas às ações públicas implementadas, assegurando assim o papel que é reservado às políticas sociais na sociedade capitalista. 


\section{Referências}

ANDERSON, Perry. Balanço do neoliberalismo. In: SADER, Emir. GENTILI, Pablo. (orgs.). Pós-neoliberalismo: as políticas sociais e o Estado democrático. Rio de Janeiro: Paz e Terra, 1995.

BEHRING, Elaine Rossetti. Estado no Capitalismo: notas para uma leitura crítica do Brasil recente. In: BEHRING, Elaine; BOSCHETTI, Ivanete; LIMA, RITA DE L. de. Marxismo, política social e direitos. São Paulo: Cortez, 2018.

BIANCHETTI, Roberto Gerardo. O modelo neoliberal e as políticas educacionais. São Paulo: Cortez Editora, 1996.

BRANCO, Rodrigo Castelo. O novo desenvolvimenstismo e a decadência ideológica do estruturalismo latino americano. In: Revista Oikos, Rio de Janeiro, volume 8, n. 1, p. 1-11, 2009.

BRAVO, Maria Inês Souza; CORREIA, Maria Valéria Costa. Desafios do controle social na atualidade. Revista Serviço Social \& Sociedade, São Paulo, n. 109, p. 126-150, jan./mar. 2012.

BRESSER PEREIRA, Luiz Carlos. Os primeiros passos da reforma gerencial do Estado de 1995. In: D'INCAO, Maria Angela; MARTINS, Hermínio (orgs): Democracia, crise e reforma: estudos sobre a era Fernando Henrique Cardoso. São Paulo: Paz e Terra, 2010. Disponível em:

<http://bresserpereira.org.br/Papers/2010/Os_primeiros_passos_reformar_gerencial_esta do_1995.pdf>. Acesso em: 15 de jan de 2020.

CALEGARE, Marcelo Gustavo Aguilar; SILVA JÚNIOR, Nelson. A construção do terceiro setor no Brasil: da questão social à organizacional. Psicologia Política, São Paulo, v. 9, n. 17 p. 129-148, jan./jun. 2009.

FIORI, José Luis. Brasil no espaço. Petrópolis, Rio de Janeiro: Vozes, 2001.

FMI. Relatório anual 2018 - síntese: construir um futuro compartilhado. [Washington: FMI, 2018]. Disponível em: https://www.imf.org/external/pubs/ft/ar/2018/eng/assets/pdf/imfannual-report-2018-pt.pdf. Acesso em: 12 fev. 2020.

FONTES. Virginia. Sociedade civil. In: FUNDAÇÃO OSWALDO CRUZ. Escola Politécnica de Saúde Joaquim Venâncio. Dicionário da educação profissional em saúde. Rio de Janeiro: [Fiocruz], 2009. Disponível on line: http://www.sites.epsjv.fiocruz.br/dicionario/verbetes/ socciv.html. Acesso em: 23 mar. 2020.

FRIEDMAN, Milton. Capitalismo e liberdade. São Paulo: Editora Artenova, 1962.

GRAMSCI, Antonio. Cadernos do cárcere. Rio de Janeiro: Civilização Brasileira, 1999. v. 1.

IAMAMOTO, Marilda Vilela. Renovação e conservadorismo no Brasil. 6 ed. São Paulo: Cortez, 2002. 
MARX, Karl. Textos Filosóficos. São Paulo: Biblioteca do Socialismo Científico: Editorial Estampa, 1975.

MÉSZÁROS, Istvam. Para além do capital: rumo a uma teoria da transição. São Paulo: Boitempo, 2002.

MÉSZÁROS, Istvam. O século XXI: socialismo ou barbárie. São Paulo: Boitempo Editorial, 2003.

SAMPAIO JR, Plínio Arruda. Desenvolvimentismo e neodesenvolvimentismo: tragédia e farsa. Revista Serviço Social \& Sociedade, São Paulo, n. 112, p. 672-688, out./dez. 2012.

MORAES, Reginaldo Corrêa Estado e política social na década de 90. In: NOGUEIRA, Francis M. Guimarães (org.). Estado e políticas sociais no Brasil. Cascavel: EDUNIOESTE, 2001.

WARDE, Mirian Jorge. Liberalismo e Educação. 1984. Tese (Doutorado em Educação) Pontifícia Universidade Católica de São Paulo, São Paulo, 1984. 